\title{
DISTRIBUTION OF SELECTED SUBSTANCES IN BLUE VARIETIES OF TABLE GRAPES
}

\author{
I. SOURAL ${ }^{a *}$, S. WenDELIN ${ }^{b}$ and J. BALíK ${ }^{a}$ \\ ${ }^{a}$ Department of Post-Harvest Technology of Horticultural Products, Faculty of Horticulture, Mendel University in \\ Brno, Valtická 337, 69144 Lednice. Czech Republic \\ ${ }^{\mathrm{b}}$ Höhere Bundeslehranstalt und Bundesamt für Wein- und Obstbau, Federal College and Research Institute for \\ Viticulture and Pomology, Wiener Straße 7, A-3400 Klosterneuburg. Austria
}

(Received: 28 June 2018; accepted: 6 November 2018)

This study contains data of seven blue cultivars of table grape (Vitis vinifera L. and Vitis labrusca L.): Attika, Early Cardinal, Eszter, Chasselas rosé, Königliche Esther, Muscat bleu, and Nero. The following were determined in intact berries: malic, tartaric, and titratable acids, $\mathrm{pH}$ values, sugar content, and antioxidant capacity. Concentrations of the following compounds were determined in the pulp of analysed berries: phenolic acids and catechins. The last analysis focused on skins; in addition to the same phenolic acids and catechins, excluding epicatechin, analysed from pulp; ferulic acid and stilbenes were also studied. Higher contents of procyanidin B2 and gallic acid were found in the pulp as compared to those found in skins. Studies during the ripening stage showed that the higher ratio of procyanidin B2 and gallic acid concentrations in the pulp vs. skins relates to late-ripening cultivars, while for earlyripening cultivars a lower ratio was observed. Contents of phenolic acids, catechin, stilbenes, and anthocyanins were studied by means of LC-DAD; other compounds were measured by FTIR.

Keywords: Vitis vinifera L. and Vitis labrusca, phenolic acids, catechins, stilbenes, anthocyanins, acidity

Grapes are one of the best-known types of fruit and play a role in nutrition as a commodity to produce wine, must, juice, syrup, raisin, table grape, and other food products. Unlike wines with considerable alcohol content, table grape can be consumed by the major part of the population including children, pregnant women, and other groups. In addition to the prevailing compounds such as water, sugars, and acids, other compounds with positive effects on human health are also present in grape/wine, mainly secondary metabolites, e.g. phenolic acids (LóPEZ-Gutiérrez et al., 2016), anthocyanins (Li et al., 2009), stilbenes (BAVARESCO et al., 2016), catechins (Mikes et al., 2008), and other members of the polyphenol group. Unfortunately, many of these phenolic compounds were destroyed as waste in wine production in the past decades, e.g. stems, grape pomace, and wine lees (CVInER et al., 2017). Phenolic acids can be classified as two groups of derivatives according to their metabolism: benzoic and cinnamic acids (Li et al., 1993). Anthocyanins are present in the berry skin as pigments; their content changes during ripening, and their properties depend on $\mathrm{pH}$ and other parameters, as was described in our previous study (TomAnKova et al., 2016). Catechins and stilbenes have been studied in the last decades (BERGER \& HERRMANN, 1971), as stilbenes - more specifically resveratrol - are connected with what is referred to as 'French paradox' (GALINSKI et al., 2016). During ripening, concentrations of procyanidins decrease (JORDÃo et al., 2001). Time of ripening changes the contents of polyphenols not only in grape - a similar decrease in polyphenols was observed in other types of plant fruits as well, e.g. tomatoes and peaches

\footnotetext{
* To whom correspondence should be addressed.

Phone: +420528367266; e-mail: ivo.soural@mendelu.cz
} 
(SNURKovic, 2015). Polyphenols play a positive role in human health as well, acting as antioxidants, anticarcinogenic agents (HADI et al., 2010), antimicrobials, scavenge reactive oxygen species (Driss \& EL-BENNA, 2010), etc., and their distribution in different cultivars at different degree of ripening are studied in this manuscript.

\section{Materials and methods}

\subsection{Chemicals and standards}

ABTS (Fluka), ascorbic acid (Carl Roth, p.a.), HCOOH (Merck, p.a.), HCl 37\% (VWR), $\mathrm{K}_{2} \mathrm{~S}_{2} \mathrm{O}_{5}$ (Keller - KD), $\mathrm{CH}_{3} \mathrm{OH}$ (Promochem, HPLC), $\mathrm{HClO}_{4} 60 \%$ (Riedel-de Haën), phosphate buffer $0.5 \mathrm{mmol}^{-1}$ of $\mathrm{pH}=1.8$ [made with: $\mathrm{KH}_{2} \mathrm{PO}_{4}$ (Merck, p.a.), the $\mathrm{pH}$ was adjusted by $85 \% \mathrm{H}_{3} \mathrm{PO}_{4}$ (VWR)], $\mathrm{K}_{2} \mathrm{~S}_{2} \mathrm{O}_{8}$ (Sigma-Aldrich), Trolox (Sigma-Aldrich), and water (VWR, HPLC) were used.

\subsection{Methods and instrumentation}

HPLC measurements were performed with LC-DAD type Agilent Technologies 1200 Series, column: Agilent Zorbax SB-C18, Rapid Resolution HT, 2.1×150 mm, $1.8 \mu \mathrm{m}, 600$ bar; column temperature $40{ }^{\circ} \mathrm{C}$, flow $0.25 \mathrm{ml} \mathrm{min}^{-1}$, inject $5 \mu \mathrm{l}$. Mobile phases were: A $(0.5 \%$ $\mathrm{HCOOH}), \mathrm{B}(100 \%$ methanol). For phenolic acids and catechins the following gradients were used (B phase): $4 \%$ at $0 \mathrm{~min} ; 5 \%$ at $10 \mathrm{~min} ; 7 \%$ at $24 \mathrm{~min} ; 11 \%$ at $48 \mathrm{~min} ; 30 \%$ at 65 $\mathrm{min} ; 70 \%$ at $70 \mathrm{~min}$, and $70 \%$ at $80 \mathrm{~min}$. Detection was carried out at 280 and $320 \mathrm{~nm}$. For stilbenes and anthocyanins the following gradients were used (B phase): $3 \%$ at $0 \mathrm{~min} ; 4 \%$ at $30 \mathrm{~min} ; 18 \%$ at $45 \mathrm{~min} ; 30 \%$ at $80 \mathrm{~min} ; 30 \%$ at $95 \mathrm{~min} ; 70 \%$ at $100 \mathrm{~min}$, and $70 \%$ at $110 \mathrm{~min}$. Detection was carried out at 280,320, and $362 \mathrm{~nm}$.

FTIR type Foss Analytical A/S, WineScan Flex/Grape/Auto/SO2 was used for measuring malic acid, tartaric acid, titratable acids, and KMW (Klosterneuburg Must Weight Scale).

Antioxidant capacity was measured by UV-VIS type Agilent 8453, at $734 \mathrm{~nm}$ by ABTS method, expressed as TEAC (Trolox equivalent antioxidant capacity).

\subsection{Samples}

Table grape of V. vinifera L. (cultivar: Attika, Early Cardinal, Eszter, Chasselas rosé, Königliche Esther, Muscat bleu, and Nero) and V. labrusca L. (Concord) were studied from 3 types of samples taken from the pulp, skins, and whole berries. The grape were obtained from Rothäcker XVI/Stiftsacker vineyards (both located on small hills facing south-southeast, $180 \mathrm{~m}$ above sea level, with climatic conditions: the average temperature $9.9^{\circ} \mathrm{C}$, precipitation averages $615 \mathrm{~mm}$ ) in Klosterneuburg, Austria, in the phase of consumption maturity. To eliminate the effects of varying environmental factors, the aforementioned cultivars of grapevine were studied during a 3-year period; until analysis they were stored frozen $\left(-25^{\circ} \mathrm{C}\right)$.

Skins from whole berries were peeled manually and mixed with either $0.4 \% \mathrm{HCl}$ in $\mathrm{CH}_{3} \mathrm{OH}$ for measuring stilbenes (resveratrol, piceid) and anthocyanins (calculated as malvidin-3-glucoside), or $6 \% \mathrm{HClO}_{4}$ for measuring phenolic acids and catechins. Before analysis, both were centrifuged and filtered, than measured at 280 and $320 \mathrm{~nm}$ using LCDAD. 
Pulp from whole berries was mixed with ascorbic acid and $\mathrm{K}_{2} \mathrm{~S}_{2} \mathrm{O}_{5}$, centrifuged, and filtered to measure phenolic acids and derivatives of catechins using LC-DAD at 280 and 320 nm.

Whole berries with seeds without stems were homogenized (mixed with seed destruction by blade mixer), centrifuged, and filtered for measurement using FTIR for analysing malic acid, tartaric acid, titratable acids, and sugar contents in KMW degrees and using UV-VIS to measure antioxidant capacity via the ABTS method (SourAL et al., 2015).

\section{Results and discussion}

Average values from the 3-year period were calculated for all blue cultivars of table grape $V$. vinifera. Results are shown in Table 1 . Based on the same or similar structure, catechins (catechin, epicatechin, procyanidins B1 and B2) were calculated altogether; the same was applied to derivatives of cinnamic acids (caftaric, coutaric, fertaric, and ferulic acids) and organic non-phenolic acids (malic and tartaric acids). Two-dimensional Principal Component Analysis (PCA) was done using all values obtained for the various parts of berries of all cultivars. The first factor described $37.48 \%$ of variance, and second $22.27 \%$. In Figure $1 \mathrm{~A}$, we can see three major groups of similar compounds or locations in berries, such as cinnamic acid in the pulp and in skins grouped with non-phenolic acids and titratable acids - continuous line circle. The second group includes compounds (catechins and gallic acid) in the pulp dotted line circle. The third group is for compounds (catechins, gallic acid, stilbenes and anthocyanins) in the skin - dashed line circle.
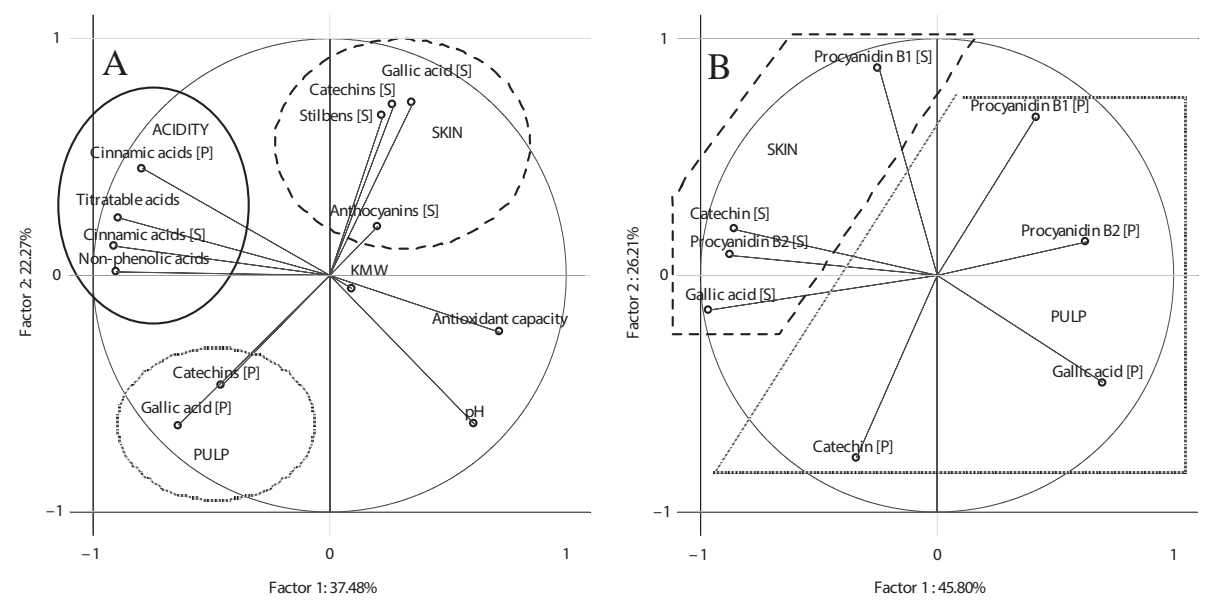

Fig. 1. Two-dimensional principal component analysis (PCA) plot of all measured parameters directly for KMW, antioxidant capacity, anthocyanins, $\mathrm{pH}$, gallic acid, and titratable acids or in groups: catechins, stilbenes, and derivatives of cinnamic acids to the left (A); and for catechins and gallic acid contents in skins and the pulp to the right (B).

$[\mathrm{P}]$ : in the pulp; [S]: in skins; without brackets: in whole berries; PULP: group of compounds in the pulp; SKIN: group of compounds in skins; ACIDITY: all acids excluding gallic acid as a minor acid. 


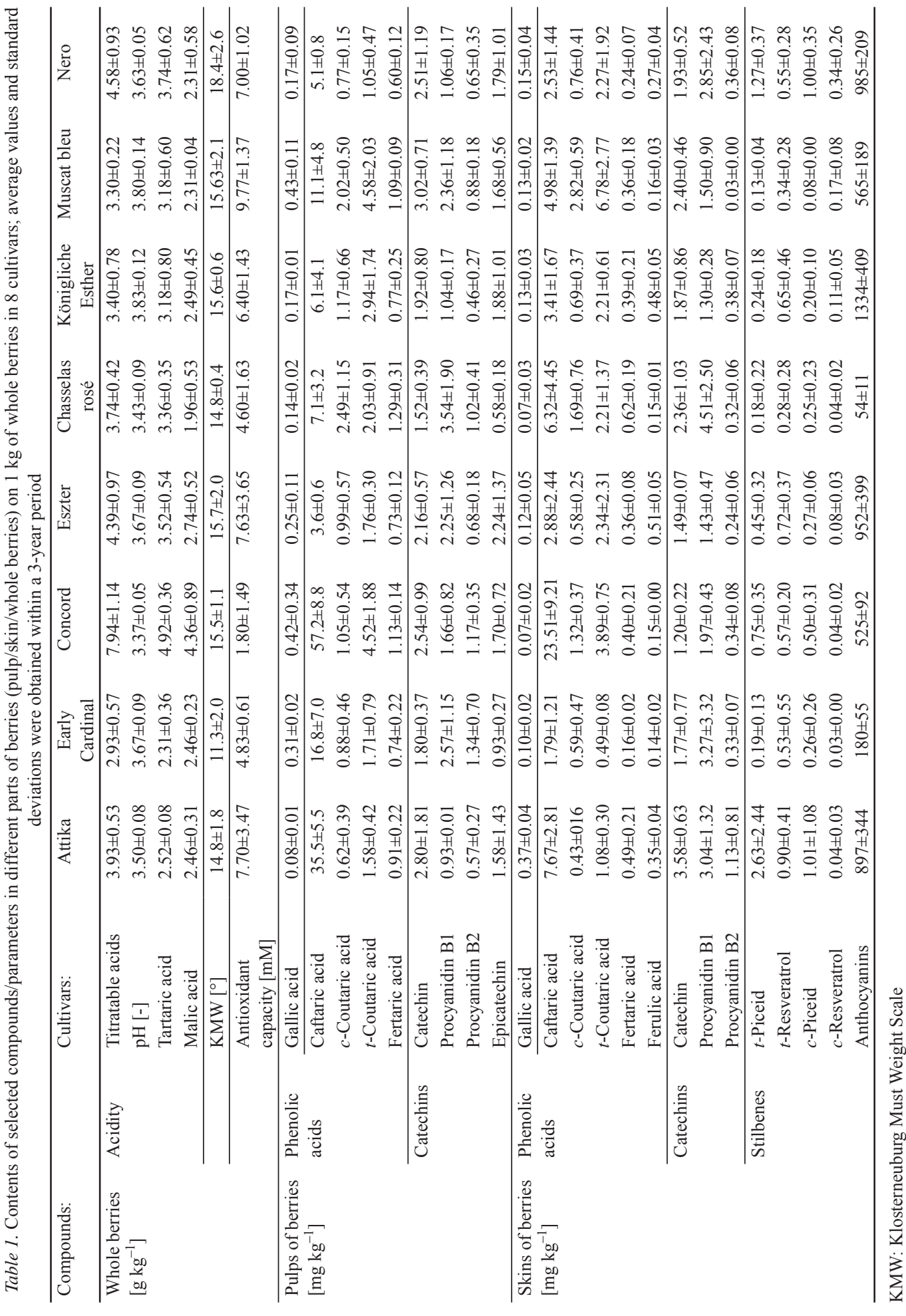




\subsection{Acidity, sugar contents, and antioxidant capacity}

Contents of acids (in circle with continuous line) are inversely proportional to values of $\mathrm{pH}$ (which increases as acidity decreases), and, similarly, but to a smaller extent, to the decrease in KMW. This phenomenon corresponds to ripening, when acidity decreases, while sugar content increases. Antioxidant capacity is inversely proportional to acidity. This is because antioxidants protect berries from blight and other threatening factors, particularly insects that attack the berries. The observed data make it clear that the increase in derivatives of cinnamic acid during ripening is not specific for skins or for the pulp but increases in both parts of the berries simultaneously. Amounts of gallic acid are negligible when compared to sum amounts of derivatives of cinnamic acid and non-phenolic acids. Contents of gallic acid and other nonacid compounds are more specific for location (skin and pulp), than acidity.

Cultivar Concord (V. labrusca) had the highest acidity with the maximum of nonphenolic acids $\left(9.28 \mathrm{~g} \mathrm{~kg}^{-1}\right)$, titratable acids $\left(7.94 \mathrm{~g} \mathrm{~kg}^{-1}\right)$, and derivatives of cinnamic acids in the pulp $\left(63.91 \mathrm{mg} \mathrm{kg}^{-1}\right)$ and in skins $\left(29.28 \mathrm{mg} \mathrm{kg}^{-1}\right)$. This corresponds to the lowest values of $\mathrm{pH}$ (3.37) and antioxidant capacity (1.80 mM of Trolox). A value in similar order of magnitude, $0.80 \mathrm{mM}$ was observed in skins of Concord (MuÑOZ-EsPADA, 2004).

\subsection{Catechins, stilbenes, gallic acid, and anthocyanins}

The trend for other compounds, such as catechins and gallic acid, was opposite to what was observed for derivatives of cinnamic acids - the higher the values for skin the lower the amounts seen in the pulp. The increase of concentrations of these two groups of compounds in skins is accompanied by an increase in contents of stilbenes and anthocyanins. The maximum levels of stilbenes $\left(4.59 \mathrm{mg} \mathrm{kg}^{-1}\right)$, catechins $\left(7.75 \mathrm{mg} \mathrm{kg}^{-1}\right)$, and gallic acid $(0.37$ $\mathrm{mg} \mathrm{kg}^{-1}$ ) were found in cultivar Attika, together with the minimum amounts for gallic acid in the pulp $\left(0.08 \mathrm{mg} \mathrm{kg}^{-1}\right)$ and a low content of catechins in the pulp $\left(5.87 \mathrm{mg} \mathrm{kg}^{-1}\right)$. The latter was nearing the minimum value of $5.30 \mathrm{mg} \mathrm{kg}^{-1}$ detected in cultivar Königliche Esther. Since anthocyanins slightly differ from the other compounds found in skins, such as gallic acid, catechins and stilbenes, cultivars where maximum and minimum levels were found were different as well (1334 $\mathrm{mg} \mathrm{kg}^{-1}$ for Königliche Esther and $54 \mathrm{mg} \mathrm{kg}^{-1}$ for Chasselas rosé).

\subsection{Pulp versus skins}

A closer look on gallic acid, catechin, procyanidin B1, and procyanidin B2, which were studied in both parts of berries (pulp and skins), the two-dimensional principal component analysis (Fig. 1B) revealed that two substances (gallic acid and procyanidin B2) were in direct contrast in terms of their contents in skins and berries - the angle between the two factors was more than 90 degree $(45.80 \%$ for the first factor and $26.21 \%$ for the second factor). Time of ripening coincided with pulp to skin ratios for these two compounds (Fig. 2). This agrees with earlier studies (OBREQUE-SLIER et al., 2012; ANDJELKOvic et al., 2013), which described that phenolic contents also change in addition to physiological properties.

Cultivars with procyanidin B2 ratio of up to 2.8 are ripening in August (Attika, Eszter, Königliche Esther, and Nero); a ratio over 3.2 was observed in cultivars ripening in September (Early Cardinal, Concord, and Chasselas rosé), and cultivar Muscat Bleu with the ratio of 30.7 is ripening in September/October. This trend particularly coincides with works of JORDÃO and co-workers (2001), who observed, for two cultivars, that amounts of procyanidins B1 and B3 in skins decreased during the maturation period, i.e. July to August; in the case of Castelão Francês, with reduction from 0.85 to $0.01 \mathrm{mg} \mathrm{g}^{-1}$ and from 0.17 to $0.01 \mathrm{mg} \mathrm{g}^{-1}$ for 
B1 and B3, respectively. A decrease was observed for Touriga Francesa cultivar as well. Unfortunately, contents in the pulp were not studied in this report. Similar results were obtained with gallic acid - cultivars with the ratio of up to 2.0 (Attika, Nero, and Königliche Esther) and Eszter (2.03) are ripening in August; cultivars with a ratio higher than 2.0 (Chasselas rosé, Early Cardinal, Muscat bleu, and Concord) are ripening in September or late September/early October. For the interpretation of the correlation no clear function (e.g. linear, exponential, etc.) was found that would actually correspond to time of ripening to amounts of various compounds, or, more specifically, pulp to skins ratio of compounds vs. time of ripening. Higher content of phenolic compounds in skin than in pulp were observed by Topalovic and Miкulic-Реткоvsek (2010), when the proportion of phenolics in pulp compared to skin ranged $14-23.9 \%$ for syringic acid, $1.2-6.3 \%$ for chlorogenic acid, $2.4-$ $12.1 \%$ for catechins, and $1.3-3.0 \%$ for total phenolics. Similarly lower values of anthocyanins in pulp than in skin were observed by $\mathrm{HE}$ and co-workers (2010).

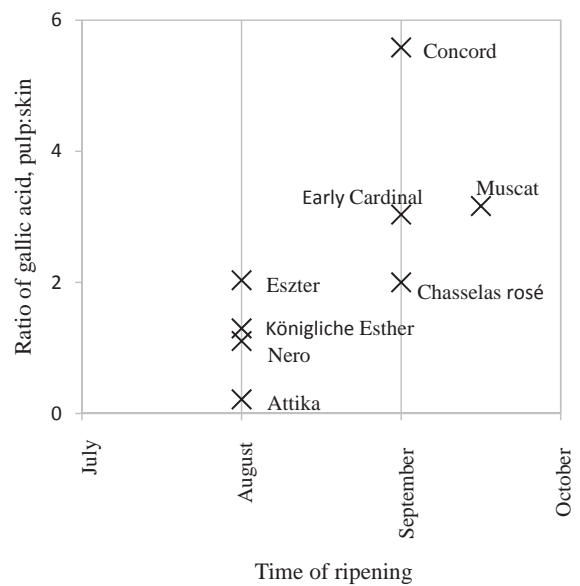

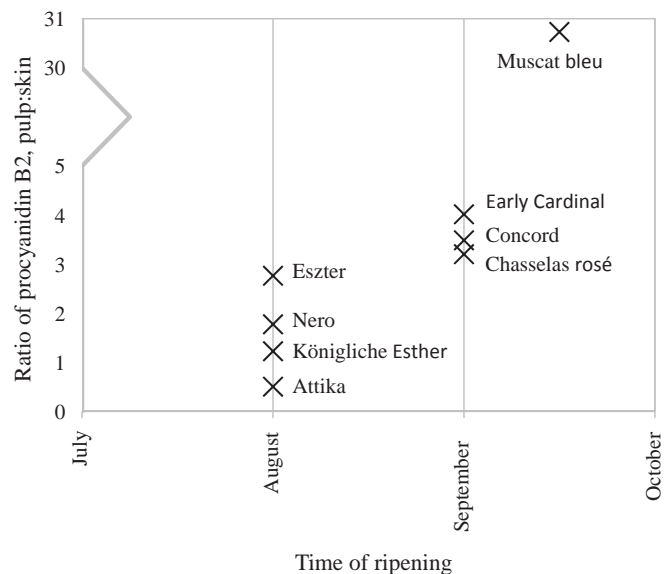

Fig. 2. Comparison of time of ripening to the pulp to skin ratio of gallic acid (A) and procyanidin B2 (B) concentrations for 8 cultivars

Correlation between procyanidin B2 and the time of harvest was studied using several types of mathematical functions, when correlation coefficient was 0.4646 for the linear function and determination indices were $0.6806,0.4460,0.9957$, and 0.6682 for the exponential, logarithmic, polynomial, and power functions, respectively. By the same method, correlation was studied between gallic acid and time of ripening. Correlation coefficient (linear function) was 0.4830 and determination indices (in exponential, logarithmic, polynomial, and power functions) were as follows: $0.4554,0.4898,0.5540$, and 0.4601 . In both cases, the highest indices were determined for the polynomial function. However, we do not assume that this mathematical characteristic actually describes ratios of compounds - rather, a gradual increase in the ratios is expected. This unstudied period opens up new possibilities of measurements for any future research into other cultivars. 


\section{Conclusions}

Blue cultivars of table grape were studied for concentrations of selected compounds in skins, pulp, and whole berries over a three-year period. Average values were studied in detail using PCA. Three clusters were formed by compounds or parts of berries: acidity (non-phenolic acids and cinnamic acids), pulp (catechins and gallic acid), and skins (non-phenolic acids and cinnamic acids, stilbenes and anthocyanins). For example, the highest average contents of measure catechins $\left(7.75 \mathrm{mg} \mathrm{kg}^{-1}\right)$ and stilbenes $\left(4.58 \mathrm{mg} \mathrm{kg}^{-1}\right)$ in skins were found in cultivar Attika. A closer look on contents of catechins with gallic acid in the pulp and in skins showed that pulp to skin ratios of gallic acid and procyanidin B2 corresponded well with the ripening time of cultivars. For cultivars ripening in August, i.e. Attika, Eszter, Königliche Esther, and Nero, the ratios were as follows: up to 2.0 for gallic acid (except for Esther: 2.03) and up to 3.0 for procyanidin B2. Higher values were found for Chasselas rosé, Early Cardinal, Muscat bleu, and Concord, which are ripening in September/October. This observed effect can be useful for future grape studies, particularly for comparison with white cultivars.

This paper was supported by the project CZ.02.1.01/0.0/0.0/16_017/0002334. Research Infrastructure for Young Scientists is co-financed from Operational Programme Research, Development and Education.

\section{References}

Andjelkovic, M., Radovanovic, B., Radovanovic, A. \& Andjelkovic, A.M. (2013): Changes in polyphenolic content and antioxidant activity of grapes cv Vranac during ripening. S. Afr. J. Enol. Vitic., 34(2), 147-155.

Bavaresco, L., Lucini, L., Busconi, M., Flamini, R. \& De Rosso, M. (2016): Wine resveratrol: From the ground Up. Nutrients, 8(4), 222, 1-8.

Berger, W.G. \& Herrmann, K. (1971): Catechins and their degradation products in grapes, husks, vinegar-wines, and corresponding vinegars. Z. Lebensm. Unters. For., 146(5), 265-274.

Cviner, P., Padrova, K. \& Kolouchova, I. (2017): Modern utilization of bio-waste from wine grape processing. Chem. Listy, 111(2), 103-108

Driss, F. \& El-Benna, J. (2010): Antioxidant effect of hydroxytyrosol, a polyphenol from olive oil by scavenging reactive oxygen species produced by human neutrophils. -in: PreEdy, V. \& WATsOn, R. (Eds) Olives and olive oil in health and disease prevention. Academic Press, Cambridge, US. pp. 1289-1294.

Galinski, C.N., Zwicker, J.I. \& Kennedy D.R. (2016): Revisiting the mechanistic basis of the French Paradox: Red wine inhibits the activity of protein disulfide isomerase in vitro. Thromb. Res., 137, 169-173.

Hadi, S.M., Ullah, M.F., Shamim, U., Hanif, S., Azmi, A.S. \& Bhat, S.H. (2010): A prooxidant mechanism of red wine polyphenols in chemoprevention of cancer. Int. J. Cancer Res. Prev., 3(3), 175-186.

He, J.-J., Liu, Y.-X., PAN, Q.-H., Cui, X.-Y. \& DuAn, C.-Q. (2010): Different anthocyanin profiles of the skin and the pulp of Yan73 (Muscat Hamburg $\times$ Alicante Bouschet) grape berries. Molecules, 15(3), 1141-1153.

JordÃo, A.M., RicARDO-DA-Silva, J.M. \& LAUREANO, O. (2001): Evolution of catechins and oligomeric procyanidins during grape maturation of Castelão Francês and Touriga Francesa. Am. J. Enol. Vitic., 52(3), 230-234.

Li, P., WANG, X.Q., WANG, H.Z. \& WU, Y.N. (1993): High performance liquid chromatographic determination of phenolic acids in fruits and vegetables. Biomed. Environ. Sci., 6(4), 389-398.

Li, X.D., Wu, B.H., Wang, L.J., Zheng, X.B., YAn, S.T. \& Li, S.H. (2009): Changes in trans-resveratrol and other phenolic compounds in grape skin and seeds under low temperature storage after post-harvest UV-irradiation. J. Hortic. Sci. Biotech. 84(2), 113-118.

López-Gutiérrez, N., Romero-González, R., Martínez Vidal, J.L. \& Garrido Frenich, A. (2016): Determination of polyphenols in grape-based nutraceutical products using high resolution mass spectrometry. LWT - Food Sci. Technol., 71, 249-259. 
Mikes, O., Vrchotova, N., Triska, J. \& Smidrkal, J. (2008): Distribution of major polyphenolic compounds in vine grapes of different cultivars growing in south Moravian vineyards. Czech J. Food Sci., 26(3), 182-189.

Muñoz-Espada, A.C., Wood, K.V., Bordelon, B. \& Watkins, B.A. (2004): Anthocyanin quantification and radical scavenging capacity of Concord, Norton, and Marechal Foch grapes and wines. J. Agr. Food Chem., 52, 6779-6786.

Obreque-Slier, E., Lopez-Solis, R., Castro-Ulloa, L., Romero-Diaz, C. \& Pena-Neira, A. (2012): Phenolic composition and physicochemical parameters of Carmenere, Cabernet Sauvignon, Merlot and Cabernet Franc grape seeds (Vitis vinifera L.) during ripening. LWT - Food Sci. Technol., 48(1), 134-141.

SNURKovic, P. (2015): Evaluation of changes in antioxidant compounds of fruit during their ripening and storage using NIR spectroscopy. Acta Hort., 1079, 507-513.

Soural, I., Balik, J., Wendelin, S. \& Eder, R. (2015): Analyses of compounds in skins, pulps and whole berries of thirty-three Austrian table grape cultivars. Acta Hort., 1079(1), 527-534.

Tomankova, E., Balik, J., Soural, I., Bednar, P. \& Papouskova, B. (2016): Colour and antioxidant properties of malvidin-3-glucoside and Vitisin A. Acta Alimentaria, 45, 85-92.

Topalovic, A. \& Mikulic-Petkovsek, M. (2010): Changes in sugars, organic acids and phenolics of grape berries of cultivar Cardinal during ripening. J. Food Agric. Environ., 8(3-4), 223-227. 